\title{
Efficiency wage and work effort: Case study of a Brazilian multinational company
}

\author{
Marina Fritoli ${ }^{1}$, Nathália Laffin ${ }^{1}$, Carlos Alberto Bonacim ${ }^{1}$, Luiz Eduardo Gaio ${ }^{2}$ and \\ Rafael Gatsios ${ }^{1^{*}}$ \\ ${ }^{1}$ Faculdade de Economia, Administração e Contabilidade de Ribeirão Preto da Universidade de São Paulo \\ (FEA-RP/USP), Brazil. \\ ${ }^{2}$ UNICAMP Universidade Estadual de Campinas, São Paulo, Brazil.
}

Received 7 August, 2020; Accepted 22 October, 2020

\begin{abstract}
This research paper explores how employees of a multinational glass manufacturing company see the pay offered by the company and how it affects, directly or indirectly, their efforts to perform their duties. For this purpose, a case study was carried out in a glass manufacturing company located in the southernern region of Brazil throughout 2017. Literature review is focused on the theoretical model based on the idea that there is a positive variation of efforts with the company supervision intensity was tested, and it pointed out that the moral hazard of being caught shirking is related to supervision. Using the Ordinary Least Square (OLS) method, the relationship between wages and supervision intensity was empirically tested, according to the model suggested by Shapiro and Stiglitz (1984), in which there is a trade-off between supervision and actual wage. The results corroborate the efficiency wage theory: $90 \%$ of the sample consider extra benefits, besides the wages, important and only $2.02 \%$ consider the wage of the greatest motivator for continuing in the company. The analyses carried out in the research present striking data regarding the employees' perception of the benefits offered. That way, the loss of these benefits may affect the collaborators' efforts. Therefore, the company must concentrate on incentive strategies towards the benefits.
\end{abstract}

Key words: Managerial accounting, shirking model, ordinary least squares.

\section{INTRODUCTION}

Efficiency wage is the idea that by paying wages above the market clearing wage, to the employees, who are considered stakeholders in the company, it is possible to obtain better effort from them and, as a result, higher economic performance when analyzing the Balance Scorecard indicators or carrying out the internal Benchmarking. If the workers are paid higher wages, the cost of losing the job becomes burdensome and that works as a benefit so that they do not wriggle out of doing their best in their duties and consider the possibility of being fired.

The aim of this paper is to design the efficiency wage empirical submodel by designing wage equations (Chengli and Yan, 2013) of automotive glass sector

*Corresponding author. Email: rafaelgatsios@hotmail.com.

Author(s) agree that this article remain permanently open access under the terms of the Creative Commons Attribution License 4.0 International License 
employees, seeking to replicate the model for other activities, to promote the effort maximization of industrial sector workers, in the countryside of Sao Paulo state in Brazil.

The study of a submodel of the Wage Efficiency Theory is relevant to the business field since it is applied in the managerial control area (Awogbenle and Iwuamadi, 2010). The worker, different from the capital, chooses his effort level and the companies set wages unilaterally. In this process, the companies, theoretically, opt not to reduce the wage up to the market balance level due to the harmful effect it would have on the employee's work effort and on his motivation as well (Appelbaum et al., 2000; Basu and Felkey, 2009).

The company also fears the possible difficult in hiring and retaining personnel, elaborating a last analysis on its profit. The literature classifies the models of employees' effort extraction, such as the Shirking Model or Labor Discipline Model, and the main authors of these models are Shapiro and Stiglitz (1984).

According to them, when workers shirk, there is the possibility of being caught, and being penalized (being fired). The balance of the model, therefore, implies unemployment since, in order to create opportunity cost to run away from effort, the companies try to increase their wages above the market clearing wage, so that the employees face a probabilistic loss (Shapiro and Stiglitz, 1984; Kahn and Sherer, 1990; Mehran and Yermack, 1997; Stiglitz, 2002).

Its theoretical applicability has more consistency in the private sector, mainly because, in the Brazilian case, the progress in the studies in the field of public-private wage differential, especially regarding the subnational governments in developing countries is little.

On this topic, the authors used the private sector as comparison parameter, especially to assess the public sector efficiency to define their wages levels. This is due to the fact that the private sector, when operating under the logic of accumulation, would find restrictions in the process of determining their employees' wages, since the wages would correspond to the workforce, a unique production factor, and their costs should be minimized in order to enable profit maximization. Other important theorists regarding the effort models are Bowles (1985) and Bulow and Summers (1986).

It is possible to absorb from this literature the information asymmetry issue between the employer (principal) and the employee (agent) regarding the employer's inability to forecast how much effort the employee will have to perform his duties and his aversion to risk, despite the fact there is a contractual relationship, since the completely comprehensive contractual design is just a theoretical abstraction (Bulow and Summers, 1986; Dow, 1987; Carmichael, 1990).

Therefore, aiming at the employment contract of automotive glass sector employees, where the effort intensity is neither something easy to measure nor well explained in legal clauses, the need of monitoring by the company becomes relevant and the shirking model can help understand the agents' behavior (Verhoogen, 2008; Bowles and Carlin, 2020).

This paper overall aim is to design the wage equation of the "Alfa Inc" employees observing through such wage equation what impacts the wage, which is referred by "w" in the shirking model and to try to represent by a survey which factors would motivate the employees' efforts since the effort "e" in the shirking model is not directly noticeable.

For case analysis, an analysis, by the Ordinary Least Squares (OLS), of the relationship between wages and supervision intensity for a multinational Brazilian company in 2017 was carried out, according to the model suggested by Shapiro and Stiglitz (1984). The results corroborate the efficiency wage theory: $90 \%$ of the sample consider extras benefits, besides the wage (Sliwka and Werner, 2017; Hansen, 2018; Power, 2018; Yap Peng Lok et al., 2019), important and only 2.02\% consider the wage as the greatest motivator for them to continue in the company.

\section{THEORETHICAL FRAMEWORK}

\section{Efficiency wage theory}

Efficiency wage is the idea that when paying wages above the market clearing wage to the employees, considered stakeholders in the company, it is possible to have better effort from them and, consequently, higher economic company performance when analyzing the Balance Scorecard indicators or carrying out internal Benchmarking.

Following Alchian and Demsetz's (1972) perspective, it is admitted that the reward obtained after the participation in an economic activity will correspond to the individual productivity. It is not by chance that the main studies presume that the agents are totally able to identify the rewards deriving from the participation in collaborative effort (Akerlof and Yellen, 1990; Williamson, 1991; Beckert, 1996).

The first empirical studies, which related wages to productivity and effort, date from the early 1950's with Slichter (1950). The author was the one who originally checked there were changes in productivity as per each employee's wage level (Akerlof and Katz, 1989; Basu and Felkey, 2009).

It is in this context that the efficiency wage theory arises. Models such as Shapiro and Stiglitz's (1984) Shirking set that the companies which pay wages above market clearing wage (efficiency wage) tend to motivate the workers due to the cost of unemployment.

The efficiency wages can enhance employees' (agents) productivity by factors related to their consumption increase, motivation and health; generate more effort and 
dedication by the workers who intend to avoid dismissal or to reach a promotion; stimulate the increase of agents' skills which may result in hiring more productive workers in face of market offer excess; and finally, reduce staff turnover, which causes, as a result, costs associated to training and the flight of jobs to other competing companies (Romer, 2006; Wilder and Lankao, 2006).

The main hypothesis linked to the efficiency wage theory is that productivity and work effort are positively correlated. Lower wages will cause the work effort to lower levels, that is, the employees will make basic effort for that wage. The efficiency wage models foresee that the companies cannot reduce their wages, even when unemployment is high, in case the productivity depends on wages (Shapiro and Stiglitz, 1985; Moll, 1993; Skott and Guy, 2007; Rizov et al., 2016; Antony et al., 2017; Asaleye et al., 2017; Mihályi and Szelényi, 2019).

The relationships between pay and company performance live with the existence of asymmetries caused by several factors, mainly agency problems, such as moral hazard. Shapiro and Stiglitz (1984), Bowles (1985) and Bulow and Summers (1986) formalize the work relations between employees and employers as a problem of agent (employees) and principal (employers). The agent-principal problem arises due to the information asymmetry between the parties involved in the contract and the impossibility, by the employer, to obtain complete information about the decision of effort intensity chosen by the employee (Beckmann et al., 2017; Gavazza et al., 2018; Acikgoz, 2019).

Such impossibility is justified, in turn, by the imperfection in tracking the effort made by the employees and the costs this supervision activity needs (Bowles, 1985; Akerlof and Yellen, 1990; Beckert, 1996; Esteves, 2008).

\section{Agency problems and incentive theory}

The information asymmetry describes the phenomenon in which some economic agents have more information than their counterpart, molding an insecure and unsure scenario. According to that concept, the uncertainty level may take on the contingent shape (random actions of nature and consumer market), and of information asymmetry, information unknown by a decision maker, but which the other agents involved in the transaction have (Williamson,1991).

The information asymmetry between employees and companies is part of an agency relationship. In this context, the contracts have an incomplete nature since the agent's actions are not contractually defined, and the principal's preferences, in general, are different from those of the agent (Mishra et al., 1998; Ba and Pavlou, 2002; Beverungen et al., 2019). The reciprocity arises as a way to align interests between both parties avoiding the achievement of suboptimal results (Cooper and Kagel, 2016; Holland, 2018).
To Milgrom and Roberts (1992), in the treatment of the incentive theory, the problem is in inducing the agent to provide several kinds of "effort". Effort is a wide metaphor, representing whatever the employee may think is burdensome and which is valuable for the employer. To Shapiro and Stiglitz (1984), high wages tend to reduce employees' demotivation when the "effort" variable is not perfectly observed. Following the same line of thought, Akerlof and Katz (1989) state that wages above the market clearing wage make an employee's moral effort increase at their tasks, working as a trade good (Sliwka and Werner, 2017; Hansen, 2018; Yap Peng Lok et al., 2019). According to Weiss (1980), higher wages attract more candidates to selection procedures and increase the hiring.

In this regard, the elaboration of an employment contract of purchase and sale of labor effort intensity is impaired, remaining, thus, the alternative possibility of elaborating an incomplete employment contract in which, the work hours and the pay are object of negotiation. Nevertheless, the intensity of the effort made by the employees in the contracted period would not be taken into consideration in the contract provisions.

Besides paying an efficiency wage, the companies can also use monitoring techniques through technology, for instance, to ensure the workers are trying hard (Skott and Guy, 2007).

Nevertheless, higher wages and means of monitoring are costly for the company. The existence of unemployment may be a factor which leads the workers to make greater effort since it is burdensome to lose the job and it may reduce the costs the companies can have with monitoring (Skott and Guy, 2007).

When the job offer is higher than the demand in the job market, the employees do not feel the cost of dismissal because they easily find a job in another company. In this situation, the company turns to the hiring of new employees, causing costs in selecting and training new workers. Therefore, seeking profit maximization, the companies are interested in paying a higher wage for which the labor supply and demand are the same (Romer, 2006; Antony et al., 2017; Mihályi and Szelényi, 2019).

As stated by Shapiro and Stiglitz (1984), involuntary unemployment is caused by asymmetric information problems, characterized by the employer-employee relationship. The employees are able to choose their effort level and in a competition situation, the workers are paid by the reservation wage and there is not unemployment. In that case, when the employee does not maximize the effort and the company notices it, he is fired and immediately rehired in the job market being paid the pre-dismissal wage.

In companies, when employee monitoring is flawed and there is a full employment situation, the workers choose not to maximize effort since the evasion does not cause them burden and it minimizes the effort to be made.

In order to reduce this shirking issue, the company 
must pay wages higher than the market clearing wage so that the employee has burden in case he is fired and is not incentivated to quit his job as well.

According to the same authors, unemployment works as a penalty for shirking (discipline mechanism) and it is considered a substitute of wage variation, as well as an incentive for monitoring (Shapiro and Stiglitz, 1984; Olawale and Garwe, 2010; Benson et al., 2020).

Therefore, the justification for developing this research is due to the existence of agency problems between the parties involved (employer and employee). In this case, considering the principal's inability to forecast his hired employees' effort (agents), the need of monitoring by the company becomes relevant, and the establishment of wage theoretical equations can help understand the employees' behavior and also help in the management of a more industry efficient system and better economic returns for the institution involved.

Studying the applicability of an efficiency wage submodel, such as the shirking model, which seeks to maximize the effort of the categories studied and avoid work evasion, through data obtained from personal wage functions of doctors and nurses can help managers to grant benefits and penalties (carrots and sticks) to influence the agents' behavior.

\section{METHODOLOGY}

In this topic, the methodological stages for carrying out the research are presented. Thus, the following methodologies will be presented: survey, wage equation and shirking model as well as their applicability in this research.

\section{Survey methodology}

First, an exploratory survey of the automotive glass maker companies in the county of Caçapava/SP which had a significant market share and in which it was possible to get in touch with the employees in order to apply a survey that was set as a theoreticalinvestigative assumption was carried out. The survey was answered by automotive glass making company employees.

The company was chosen since it is part of the oligopoly which is the automotive float market in Brazil, and which has a US\$ 6.5 billion worldwide revenue, and about 1,500 employees in its Brazilian branches. Such numbers make it a large multinational company and it will be used as Proxy for "company supervision level' variable in the conclusion of the possible applicability of the shirking model in the company.

A multiple case study was carried out in the company. First, a quantitative survey was applied, using the technique of semistructured interviews performed from a data-gathering objective questionnaire with scales regarding the research problem so that the interviewee can take a stand on the subject investigated, without having to write down the answers. The SurveyMonkey was the software used to structure the online research.

As primary result, 150 statistically valid surveys were obtained. They were answered directly by strategic, managerial and operational level employees and it covered all the areas of the company to mitigate purposeful consensus of the answers and try to investigate some factors which portrait the reality of the company, despite having been assessed subjectively (by personal answers).

The survey used was developed solely for this purpose and it also has fundamental questions to find important variables to mold the wage equation for the employees and to enable the use of the Ordinary Least Square method. Since the aim was to observe a possible corroboration of the shirking model theory in the company, the search for the perception of each employee has of his own pay and the factors which motivate his efforts were relevant since the agents are fully able to identify rewards deriving from their participation in cooperative effort and that the employees' wages can increase their productivity due to issues linked to the increase in consumption, their motivation and health; generate greater effort and dedication by the workers who intend to avoid dismissal or to be promoted; it is a stimulus to enhance agents' skills which may result in hiring more productive workers in face of the excess of market offer, and finally, decrease the turnover of workers, which, consequently, generate costs associated to the training and flight for jobs in other companies.

It is also necessary to remember that high wages tend to reduce employees' discouragement when the "effort" variable is not perfectly observed. Through the survey, better observation of the effort motivator is sought. The research was totally voluntary and regulated by ethical criteria and the respondents signed an informed consent form.

Two sets of questions were developed for the survey. The first one regards the effort and pay and which gradation in the possibilities of answers will allow the elimination of poorly answered surveys with the outlier statistical exclusion when, for instance, all the questions are answered in only one gradation. Within this same purpose, more specific questions regarding an issue are asked and, after that, a more general question is asked to analyze whether the interviewee gets on contradiction.

The second part, which also has a straightforward nature, tries not to spend too much of the workers' time and not to be so intrusive, regarding the wages, pecuniary and non-pecuniary benefits and risks.

Finally, after data collection, the content of the answers was changed into comparative graphs between the category of the professionals, analyzing the risk perception and effort motivation of the company different areas for the authors' understanding and, thus, a theoretical wage equation was modeled for the categories of the professionals through answers such as age, experience, gender, etc., so that, afterwards, by using the OLS, we could compare the result to the shirking model theory given the answer scenario in relation to the effort, wages and risks.

The answers were delivered more often from September 15 th to September 22nd, 2017, since it was when the company had the effective authorization of the board of directors and disclosed the survey link via mass mailing to the roster of employees which was provided by the human resource department.

Regarding the survey on effort and motivation, it is known that the answers for the statements made followed the agreement scale: 1 - Strongly disagree; 2 - Disagree somehow; 3 - neither disagree nor agree; 4 - Agree somehow; 5 - Strongly agree. Next, there is a summary chart of the answers to this survey questions (Chart 1).

The second part of the survey on remuneration, benefits and risks followed a three-option agreement scale: strongly disagree, strongly agree, no formed opinion, and about that, there is: the company pays within the date set and the correct amount, it tends to be transparent regarding its employees' paycheck right at the work contract. The answers are reproduced in Chart 2 . The analyses of the surveys with the other items of the research are shown in this paper's topic of the results.

\section{Wage equation methodology}

A theoretical wage equation will be designed in accordance with the 
interviews, from individual information absorbed by the survey identifying what actually affects the perception of wage by the employee and how the company could supposedly develop the equation.

It is believed that human capital is the first important feature. It is usually observed through the following variables: years of formal education, experience and how long the worker has worked in the company. In our survey, these variables are encompassed in the questions: professional training, field of work in the company and how long he/she has worked for the company. The main criticism to the use of these variables is that they express other social processes and phenomena besides the stricto sensu human capital.

In particular, regarding the worker remaining in the company, it can also be considered Proxy for the existence of internal job markets since it captures elements of job demand, such as stability, turnover cost reduction and less company sensitivity regarding the economic cycle.

Additionally, the paper analysis will include the variables: size of the company, gender of the workers and occupation. The first variable intends to capture the fact that larger companies present a greater capital-work relationship; they have some level of influence to determine the price of the product or are oligopolistic and present more organized workforce. Given these features, it is expected that wage is a growing function in the company size.
The "gender" variable was introduced to assess the prejudice level, to be detected by the fact that workers with the same productive attributes earn different remuneration. In perfect competition, it is hoped there is no prejudice since a company would not be able to get female workforce by paying her below the marginal productivity. On the other hand, if it wanted to pay his male workforce a wage higher than the marginal productivity, it would not be maximizing the long-term profit. Prejudice, nevertheless, when the situation is not that of perfect competition, may exist. In that case, profit reduction does not make the company unprofitable. This practice will be collected, in this study, through a dummy variable (male=0; female $=1$ ) in which the expectation, in case of prejudice, is a negative coefficient.

The occupation variables will be defined through the dummies and aim to assess the competition theory per occupation, in which the wage is related to the work position and to the marginal productivity of the worker in that position.

Positive coefficients indicate remuneration higher than that associated to the marginal productivity deriving from the person's personal attributes.

The variables which will be used to compose the wage equation model are listed in Equation 1 which, in accordance with the view of the company obtained up to this point, is proposed (Bulow and Summers, 1986):

$$
\begin{aligned}
& W w=\beta o+\beta_{1} A w+\beta_{2} W s+\beta_{3} I d+\beta_{4} L w+\beta_{5} G e+\beta_{6} N e+\beta_{7} T c+\beta_{8} \mathrm{He}+ \\
& \beta_{9} T l+\beta_{10} Q w+\beta_{11} N q w+\beta_{12} S p+\varepsilon
\end{aligned}
$$

where $\mathrm{Ww}=$ worker's wage neperian logarithm $\mathrm{i} ; \mathrm{Aw}=$ average wage (in minimum wages); Ws = worker's schooling years $\mathrm{i}$; $\mathrm{ld}=$ age; $L w=$ how long the worker $\mathrm{i}$ stays in the company; $\mathrm{Ge}=$ Gender i ( $0=$ male; $1=$ female); $\mathrm{Ne}=$ number of employees of the company the worker i works for; $=1500$ is constant; Tc $=$ turnover of the company the worker i works for (dismissals + admissions)/(admissions + number of employees).

The dismissals and admissions are given by the averaGe in a year and the number is provided by the company $=22 \%$ is constant. $\mathrm{He}=$ higher education occupation (dummy=1:yes;:=0:no); $\mathrm{TI}=$ technical level occupation (dummy=1:yes; $=0: n o$ ); $\mathrm{Qw}=$ qualified or semi-qualified worker who works in area $X$ (dummy $=1$ :yes; $=0: n o$ )having, at least five years in the company and at least complete higher education/ complete technical education. Nqw $=$ nonqualified worker (dummy=1:yes; $=0:$ no)- having less than five years in the company and, at most, incomplete higher education. $\mathrm{Sp}=$ Number of Supervisors/subordinates in the area $=$ on averaGe, it is equal to $1 / 20=0.05$; $e=$ error .

Number of Supervisors/Number of Subordinates $=1 / 20$.

That provides an average of 75 supervisors within 1,500 employees. The regressions were calculated in the Gretl econometrics software.

\section{Shirking model methodology and applicability in this research}

The model assumes a fixed number of workers with identical characteristics whose utility is $U=(w+e)$, in which " $w$ " represents the wage rate explained in the previous wage equation per Sai and "e", the effort. The choice of workers in relation to the effort is restricted to two values: $\mathrm{e}=0$ (shirker) and e $>0$ (non-shirker).

Workers with effort $(e>0)$ will always be employed at wage "w". On the other hand, the workers who choose the $e=0$ strategy take the risk of being dismissed with a probability equals to " $q$ " at each period (or unit) of time (Esteves, 2006).

In case of being unemployed, the workers have a benefit equals to "b". The worker who chooses the shirking strategy, alternates from periods of employability to those of unemployment, in which $\theta \theta$

is the fraction of time in which the shirker worker is employed (Esteves, 2006).

The utility functions for non-shirker and shirker workers are, respectively, equals to:

$$
\begin{aligned}
& U^{n=(w-e)} \\
& \mathrm{U}^{\varepsilon=(\theta) \mathrm{w}+(1-\theta)} \mathrm{b}
\end{aligned}
$$

Aiming to extract positive effort levels from their employees, the company chooses a wage rate, $w$, which implies a result for the workers, in which $\mathrm{U}^{\mathrm{n}}>\mathrm{U}^{8} \mathrm{U}^{\mathrm{n}}>\mathrm{U}^{\mathrm{s}}$ (non-shirking condition), that is, a wage rate equals to:

$\mathrm{w}>b+\frac{1}{1+\theta} \mathrm{e}$

Considering that " $q$ " is the probability of the shirker worker being caught shirking and, consequently, fired at each period (or unit) of time, thus, the expected employment duration for this worker will be $1 / \mathrm{q} 1 / \mathrm{q}_{\text {(Esteves, 2006). }}$

If $\rho \rho$ is the probability in which an unemployed worker finds a work position per period (or unit) of time, thus the expected unemployment duration will be $1 / \rho 1 / \rho$. According to these considerations, $\theta \theta$ can be written the following way:

$\theta=\frac{1 / q}{\frac{1}{q}+1 / p}$

Substituting the expression Equation 4 in Equation 3, we have: 
$\mathrm{w}>b+\left(1+\frac{\mathrm{p}}{\mathrm{q}}\right) \mathrm{e}$

Equation 5 demonstrates a positive relationship between effort "e" and salary "w". The work effort level is not directly verifiable in a subjective way, therefore, empirically testing the relationship between "w" and "e" is not possible.

Alternatively, it can be seen that Equation 5)points a trade-off between salaries ( $w$ ) and the probability of the shirker worker being caught and fired (q). If "q" varies positively with the company supervision intensity (the greater the supervision intensity, the greater the probability of detecting a shirker worker), it is also possible to infer on a trade-off between wages and supervision intensity.

The biggest problem in these empirical tests of the shirking version is the choice of the proxy variable to represent the supervision intensity. The most used proxy variables for this purpose are:

(1) Company size (the average number of employees in a company at a certain period of time is usually used); and

(2) The supervisors/number of employees ratio in a certain company or industry (known in literature as span of control).

The company has about 1,500 employees. It is estimated that $\rho \rho$ could be given by the employability statistics of the city of Caçapava, São Paulo State, Brazil, provided by the Ministry of Labor and by the Monthly Employment Research (Pesquisa Mensal de Emprego) of IBGE (2018).

\section{RESULTS AND DISCUSSION}

The result analysis begins with the presentation of a descriptive statistics of the variables presented beforehand in the research, with average values, standard deviation, maximum and minimum. After the presentation, the OLS data model is built. The descriptive analysis points the variability of the sample which validates the results presented in the OLS regression model (Tables 1 and 2).

The following estimates were obtained for the original wage equation, but adjusted by the tests applied in the research. Due to the correlation between the variables of the model, the explanatory variables of the model were chosen. The model is presented with the Lsai dependent variable and the other dependent variables which have been previously presented. As discussed previously, the hypothesis of efficiency wage sets there is a negative relationship between wage and supervision. In the terms of the Wage Equation, it is hoped that the $\beta_{12}$ expected value be negative in order to corroborate the efficiency wage hypothesis.

The 150-observation model presented good adjustment regarding the Lsai dependent variable. The dependent variables, but the Spr variable, are significant. The Rsquared of the model was 0.6478. Although the "Spr" variable is not significant in the model designed in the research, the $\beta_{12}$ is negative showing a corroboration with the efficiency wage theory. It is worth mentioning that such results must be considered with caution since the econometric model represented in the Wage Equation suggests that the sample is small (150 observations) and it considers only one company of the sector. Moreover, the supervisors/subordinates ratio is an exogenous variable.

The econometric model represented by the Wage Equation considers a very restrictive hypothesis, namely, the exogeneity of the supervisors/subordinates ratio variable (span of control). In practical terms, that implies saying that the company, by means of the profit maximization process, chooses a wage level to be paid the worker (choice which is backed in the Non Shirking Condition); nevertheless, the number of supervisors for each set of workers will be a variable in which this company will have no control.

Such problem was not solved in this paper due to the lack of necessary information and that increases the bias of the study.

It is also worth recalling the survey analysis in order to explain the non-significance of the "Spr" variable in this study. Most of the survey collaborators have high positions at the company (evidence shown by the age, remuneration and education) and, thus, they are also supervisors.

There are also 11 workforce sectors within the company and each one of them reflects a different market view. It is also possible to state that the company neither invests on a good survey of organizational climate to identify which encourages the employees' performance, nor very much on personnel continuous improvement which may cause personnel turnover and the non consideration of supervision.

The employees have also considered themselves qualified and do not see lots of benefits in the company trainings (Appendixes Table 1 and 2; Appendix Figure 1).

The sample believes to get along well with their supervisors. $74 \%$ believe they have their ideas listened to by the bosses and $67 \%$ of them think that the boss's strictness does not improve the worker's performance, that is, supervision is well-regarded by the subordinates.

Nevertheless, $46.64 \%$ of the sample do not consider the boss as a piece of effort motivation to carry out the tasks to be performed in the company, maybe because of the number of subordinates per supervisor. $90 \%$ of the collaborators think the extra benefits, besides their nominal wage, such as individual and familiar health insurance, are important. There was only $2.02 \%$ of agreement on the fact that the wage is the greatest motivator to work in the company, the majority agrees that the non-pecuniary benefits (those which are not money paid), such as status, encourage them more to keep doing their duties in the company and the benefits offered, besides the paycheck, are better than those offered by the market average.

That shows that losing these benefits would affect the worker's effort and the company should create an incentive strategy towards that. $62 \%$ of the sample also 
Table 1. Descriptive Statistics

\begin{tabular}{lccccc}
\hline Variable & Obs & Mean & Std. Dev. & Min & Max \\
\hline$W w$ & 150.00 & $6,192.40$ & $3,616.90$ & $2,130.00$ & $22,000.00$ \\
$W s$ & 150.00 & 15.07 & 2.98 & - & 22.00 \\
$l d$ & 150.00 & 36.02 & 9.88 & 22.00 & 61.00 \\
$T I$ & 150.00 & 9.15 & 7.38 & 1.00 & 25.00 \\
$G e$ & 150.00 & 0.16 & 0.37 & - & 1.00 \\
$\mathrm{Ne}$ & 150.00 & $1,500.00$ & - & $1,500.00$ & $1,500.00$ \\
$T c$ & 150.00 & 0.22 & - & 0.22 & 0.22 \\
$H e$ & 150.00 & 0.69 & 0.47 & 1.00 & 1.00 \\
$T I$ & 150.00 & 0.05 & 0.22 & - & 1.00 \\
Qw & 150.00 & 0.61 & 0.49 & - & 1.00 \\
$S p$ & 150.00 & 0.07 & 0.02 & 0.05 & 1.00 \\
Nqw & 150.00 & 0.39 & 0.49 & - & 1.00 \\
$W w$ & 150.00 & 8.58 & 0.54 & 7.66 & 9.99 \\
\hline
\end{tabular}

Source: created by the authors (2018).

Table 2. Estimates of the 4 OLS Model.

\begin{tabular}{lccc}
\hline Dependent variable & Coefficient & Standard Deviation & P-Value \\
\hline Ws & $0.04^{* * *}$ & 0.01 & 0.00 \\
$I d$ & $0.01^{* * *}$ & 0.01 & 0.01 \\
$\mathrm{TI}$ & $0.01^{*}$ & 0.01 & 0.09 \\
$\mathrm{Ge}$ & $-0.22^{* *}$ & 0.09 & 0.02 \\
$\mathrm{He}$ & $0.34^{* * *}$ & 0.11 & 0.00 \\
$\mathrm{TI}$ & -0.17 & 0.20 & 0.40 \\
$\mathrm{Nqw}$ & -0.08 & 0.10 & 0.43 \\
$\mathrm{Sp}$ & -1.79 & 1.71 & 0.30 \\
Const. & $7.24^{* * *}$ & 0.33 & 0.00 \\
\hline
\end{tabular}

***Significance level of $0.01,{ }^{* *}$ Significance level of 0.05 , *Significance level of 0.10 . Source: created by the authors (2018).

consider the possibility of changing jobs in a short-time as something remote because he/she is motivated. However, the company should take into account the vigilant profile of their employees in face of the job opportunities in the other companies in the market since it represents evasion risk and recruiting and training costs of personnel who may not be seized. Finally, most of the employees consider themselves dismissal-risk averse.

All the previous factors corroborate the Shirking Model theory since the incentive the company offers the employee so that he keeps his effort behavior is in the idea that the risk of losing the job becomes "burdensome" because it entails the loss of benefits which are considered advantageous by the worker in his preference ranking.

\section{Conclusion}

The efficiency wage theory suggests that the companies have better economic results when they pay their employees wages or benefits higher than those determined by the market. Wages higher than the market clearing wage induces the worker to try hard, and the higher wage would entail penalty in case of dismissal.

Through this study, it was possible to absorb relevant company information which, because of being limited, is not required to disclose much information, but, that does not implies it can not benefit from the study on corporate governance and controllership.

From the Shirking Model presented in this paper (Shapiro and Stiglitz, 1984), it is concluded that wages must increase when (1) the effort is more costly in terms of utility for the worker (higher e); (ii) the unemployment utility is greater; (iii) the interest rate is greater; (iv) the $b$ probability (separation due to reallocation) is greater; $(\mathrm{v})$ the probability of being caught "dragging your feet" (small q) is lower.

The theoretical model based on the idea there is a $q$ positive variation on the company supervision intensity, 
that is, the greater the supervision intensity on the workers, the greater the probability of detecting a shirker worker. Thus, it is possible to infer a trade-off between wages and supervision intensity. The empirical literature follows this argument. The study provided alternative tests for the efficiency wage theory (shirking model) by using the estimate methodology: (i) OLS.

Nevertheless, a problem related to this kind of test is that other factors could be contributing for a positive correlation between wages and company size. An alternative hypothesis is that larger companies pay higher wages to make up for potential disadvantages such environments provide, for instance, the impersonality of the relationships within these types of organizations.

The lesson learned is corroborated by the theory of the shirking model, as the incentive that the company offers to the employee for maintaining effort behavior is based on the concept that the risk of losing the position becomes "onerous" because it implies a loss of benefits considered advantageous by the employee in his/her preference ranking. Moreover, along this line of reasoning, the study asserts that the greater the intensity of supervision over workers, the greater the probability of detecting a shirker worker. Thus, it is possible to infer a trade-off between salaries and supervisory intensity.

From the data analysis, information regarding the wage-supervision relationship was obtained. In this respect, the results corroborate the efficiency wage theory: $90 \%$ of the sample consider extra benefits besides the wages important and only $2.02 \%$ consider the wage the greatest motivator for continuing in the company.

The analyses carried out in the research present overwhelming data regarding the employees' perception in face of the benefits offered. In this sense, the loss of these benefits can affect the collaborators' efforts. Thus, the company must concentrate invecentive strategies towards the benefits.

\section{CONFLICT OF INTERESTS}

The authors have not declared any conflict of interests.

\section{ACKNOWLEDGEMENTS}

The authors are very pleased with the Human Resources $(\mathrm{HR})$ Manager and the staff of the Human Resources Department of the "Alfa Inc" for their insightful support on the development of the case study.

\section{REFERENCES}

Acikgoz Y (2019). Employee recruitment and job search: Towards a multi-level integration. Human Resource Management Review 29(1):1-13.

Akerlof GA, Katz LF (1989). Workers' trust funds and the logic of wage profiles. The Quarterly Journal of Economics 104(3):525-536.
Akerlof GA, Yellen JL (1990). The fair wage-effort hypothesis and unemployment. The Quarterly Journal of Economics 105(2):255-283.

Alchian AA, Demsetz H (1972). Production, information costs, and economic organization. The American Economic Review 62(5):777795.

Antony J, Klarl T, Lehmann EE (2017). Productive and harmful entrepreneurship in a knowledge economy. Small Business Economics 49(1):189-202.

Appelbaum E, Bailey T, Berg P, Kalleberg AL, Bailey TA (2000). Manufacturing advantage: Why high-performance work systems pay off. Cornell University Press.

Asaleye AJ, Olurinola I, Oloni EF, Ogunjobi JO (2017). Productivity growth, wages and employment nexus: Evidence from Nigeria. Journal of Applied Economic Sciences 12(5):1349-1362.

Awogbenle AC, Iwuamadi KC (2010). Youth unemployment: Entrepreneurship development programme as an intervention mechanism. African Journal of Business Management 4(6):831-835.

$\mathrm{Ba}$ S, Pavlou PA (2002). Evidence of the effect of trust building technology in electronic markets: Price premiums and buyer behavior. MIS Quarterly 26(3):243-268.

Basu K, Felkey AJ (2009). A theory of efficiency wage with multiple unemployment equilibria: how a higher minimum wage law can curb unemployment. Oxford Economic Papers 61(3):494-516.

Beckert J (1996). What is sociological about economic sociology? Uncertainty and the embeddedness of economic action. Theory and Society 25(6):803-840.

Beckmann M, Cornelissen T, Kräkel M (2017). Self-managed working time and employee effort: Theory and evidence. Journal of Economic Behavior and Organization 133:285-302.

Benson A, Sojourner A, Umyarov A (2020). Can reputation discipline the gig economy? Experimental evidence from an online labor market. Management Science 66(5):1802-1825.

Beverungen D, Müller O, Matzner M, Mendling J, Vom Brocke J (2019). Conceptualizing smart service systems. Electronic Markets 29(1):718.

Bowles S (1985). The production process in a competitive economy: Walrasian, neo-Hobbesian, and Marxian models. The American Economic Review 75(1):16-36.

Bowles S, Carlin W (2020). What students learn in economics 101: Time for a change. Journal of Economic Literature 58(1):176-214.

Bulow JI, Summers LH (1986). A theory of dual labor markets with application to industrial policy, discrimination, and Keynesian unemployment. Journal of labor Economics 4(3 Part 1):376-414.

Carmichael HL (1990). Efficiency wage models of unemployment-one view. Economic Inquiry 28(2):269-295.

Chengli Z, Yan C (2013). Motivating innovation with a structured incentives scheme Extending the Manso model. African Journal of Business Management 7(37):3747-3753.

Cooper DJ, Kagel JH (2016). Other-regarding preferences. The handbook of experimental economics $P 217$.

Dow GK (1987). The function of authority in transaction cost economics. Journal of Economic Behavior and Organization 8(1):13-38.

Esteves LA (2006). Uma nota sobre intensidade de supervisão nas indústrias brasileiras. Revista Brasileira de Economia 60(3):235-246.

Esteves LA (2008). Salário eficiência e esforço de trabalho: evidências da indústria brasileira de construção. Revista Economia 9(2):327341.

Gavazza A, Mongey S, Violante GL (2018). Aggregate recruiting intensity. American Economic Review 108(8):2088-2127.

Hansen TB (2018). Wages of violence: Naming and identity in postcolonial Bombay. Princeton University Press.

Holland DS (2018). Collective Rights-Based Fishery Management: A Path to Ecosystem-Based Fishery Management. Annual Review of Resource Economics 10:469-485.

Kahn LM, Sherer PD (1990). Contingent pay and managerial performance. ILR Review 43(3):107-S.

Mehran H, Yermack D (1997). Compensation and top management turnover. Available https://papers.ssrn.com/sol3/papers.cfm?abstract_id=1297755

Mihályi P, Szelényi I (2019). Rent-Seekers, Profits, Wages and Inequality. Springer International Publishing.

Milgrom P, Roberts J (1992). Economics, Organization and 
Management, Pren, tice Hall. Inc., Englewood Cliffs, New Jersey.

Mishra DP, Heide JB, Cort SG (1998). Information asymmetry and levels of agency relationships. Journal of Marketing Research 35(3):277-295.

Moll PG (1993). Industry wage differentials and efficiency wages: a dissenting view with South African evidence. Journal of Development Economics 41(2):213-246.

Olawale F, Garwe D (2010). Obstacles to the growth of new SMEs in South Africa: A principal component analysis approach. African Journal of Business Management 4(5):729-738.

Pesquisa Industrial Anual (2018). IBGE-Instituto Brasileiro de Geografia e Estatística, 2018.

Power L (2018). Employee Group Benefit Insight: An Informal Reference Guide. Archway Publishing.

Rizov M, Croucher R, Lange T (2016). The UK national minimum wage's impact on productivity. British Journal of Management 27(4):819-835.

Romer D (2006). Advanced macroeconomics. McGraw-Hill, Irwin. Massachusetts: Boston.

Shapiro C, Stiglitz JE (1984). Equilibrium unemployment as a worker discipline device. The American Economic Review 74(3):433-444.

Shapiro C, Stiglitz JE (1985). Can unemployment be involuntary? Reply. The American Economic Review 75(5):1215-1217.

Skott P, Guy F (2007). A model of power-biased technological change. Economics Letters 95(1):124-131.

Slichter SH (1950). Notes on the Structure of Wages. The Review of Economics and Statistics 32(1):80-91.

Sliwka D, Werner $P$ (2017). Wage increases and the dynamics of reciprocity. Journal of Labor Economics 35(2):299-344.
Stiglitz JE (2002). Employment, social justice and societal well-being. International Labour Review 141(1-2):9-29.

Verhoogen EA (2008). Trade, quality upgrading, and wage inequality in the Mexican manufacturing sector. The Quarterly Journal of Economics 123(2):489-530.

Weiss A (1980). Job queues and layoffs in labor markets with flexible wages. Journal of Political Economy 88(3):526-538.

Wilder M, Lankao PR (2006). Paradoxes of decentralization: Water reform and social implications in Mexico. World Development 34(11):1977-1995.

Williamson OE (1991). Comparative economic organization: The analysis of discrete structural alternatives. Administrative Science Quarterly 36(2):269-296.

Yap Peng Lok S, Ng LC, Kumari P, Hwa EP (2019). The Impact of Compensation System on Pay Satisfaction in the Banking Industry in Malaysia: A Proposed Framework. Global Business and Management Research 11(2):61-72. 


\section{APPENDIX}

Chart 1. Summary chart of the survey on effort and motivation.

1. "The company has been doing whatever is necessary to keep its employees motivated to perform their duties": $38 \%$ agree somehow, $16 \%$ neither disagree nor agree, $22 \%$ disagree somehow, and $9 \%$ strongly disagree with the statement. Since the acceptance scale goes from 0 to 5 points, the average of the answers rated the company as being 3.28 in this answer, that is, the company is above the average on the motivational aspect.

2. "The company tries to know the economic needs and individual career goals via tracking surveys". Regarding the second statement in this section, 34\% of the interviewees strongly disagree and about $18 \%$ disagree somehow, $19 \%$ neither disagree nor agree, $22 \%$ agree somehow and only $7 \%$ strongly agree. Such heterogeneity in the answers resulted in an average which rates the company in 2.50 in the tracking aspect. Despite being in the average of the point scale, the company assessment in this aspect by the profile of high position employees who answered the questions suggests that the company does not invest or is unable to demonstrate a good organizational climate survey.

3. "Ability to perform their position duties": More than $90 \%$ of the staff feels confident due to the educational background and experience in the market to carry out the duties which are assigned to them in the company routine and that affects directly the company performance positively because it reduces personnel training and retraining costs. This result influences directly the fourth statement in this section.

4. "The company offers useful professional improvement training": $16 \%$ strongly agree, $32.32 \%$ agree somehow, $12.12 \%$ neither disagree nor agree, $15 \%$ disagree somehow and $24 \%$ strongly disagree. The average for this question was 3.01 . Thus, the training which is offered by the company seems useless for the employees performance improvement in their point of view.

5. "In my opinion, the skills and good professional performance of the employee are taken into account in order to get a promotion in the company": $27 \%$ strongly agree, $41 \%$ agree somehow, $14 \%$ neither disagree nor agree, $8 \%$ disagree somehow and $10 \%$ strongly disagree. The average for this question was 3.67. Statistics show that the employees agree with the company merit based policies and that the promotion of positions in general takes place by an employee"s differential performance.

6. "In order to be promoted in the company, you just have to be indicated by a supervisor who has the power to do it": $24 \%$ agree somehow, 30\% neither disagree nor agree, 17\% disagree somehow and 10\% strongly disagree. The result was 3.23 average, which is very close to the average of the last question. Such ascertainment shows the position of those who answered the survey regarding the promotion since most of them agree that the promotion is a consequence of individual merit and $42 \%$ agree somehow that in order to be promoted, being indicated by a powerful supervisor is also necessary. One statement does not exclude the other. The scenario shows, therefore, that the company also has a well defined hierarchy in delegating roles.

7. "I have already felt frustrated for thinking I deserved a promotion, but I did not get it. That affected or affects the effort I make to do my duties somehow": For $34 \%$ of the employees, not having been recognized with a promotion affected their performance of the duties they had in the present position and $36 \%$ disagree somehow that the company policy has not affected their performance. Since the percentage of those who neither disagree nor agree added up to $20 \%$, it is possible to conclude that the answer to the question varies very much according to each employee"s feelings, but, on average, the company has a median assessment (in the 1 to 5 point scale) in recognizing meritocracy and that may negatively impact their employee"s efforts.

8. "The company offers health insurance and company discounts for me and my relatives, which, in my opinion, is worthwhile": Almost $90 \%$ of the employees consider the pecuniary benefit of individual and family health insurance important. The average for this aspect was 4.54 ( in the 1 to 5 point scale).

9. "My boss and I get along well": almost $91 \%$ of the employees believe they get along well with their direct supervisor. Since it was previously explained to the employees that the survey would be independent from the company and with all the identificati on and the personal answers preserved, it is not believed that the fear of exposing themselves has affected the respondents" criteria. Only $2.04 \%$ said they strongly disagree with the statement, three people out of 150 .

10. "The boss is always encouraging me/ encouraging the team who I work with": It can be seen that there was not criteria deviation in this tenth statement because $46.64 \%$ does not see the boss as an effort motivation part in individual and team tasks. $27.55 \%$ agree somehow with the same question and $25.51 \%$ strongly agree, showing closeness to the data gathered in the previous statement and setting a 3.55 average. A scenario in which the subordinates see a good relationship with their supervisors, but in which the supervisor is not a part of the effort motivation is built. It is worth highlighting that acco rding to the data provided by the company, there are, on average, 20 employees to each supervisor.

11. "Which motivates me the most to work for this company is the paycheck": only $2.02 \%$ strongly agree. $25.25 \%$ agree somehow, 35.35\% neither disagree nor agree (which is a three level agreement in the 1 to 5 point scale), 29.29\% disagree somehow and $8.08 \%$ strongly disagree, which results in a 2.84 average for this aspect. This statistics must be analyzed together with the survey, including the second part that is about wage and risks. Nevertheless, it was previously concluded that $37 \%$ of the sample believe there are other motivators besides the paycheck which influence their stay in the company. 
Chart 1. Cont'd

12. "My food and housing needs are being fulfilled": $73 \%$ of the sample are satisfied with the return they have from the company and use them in their food and housing needs.

13. "The possibility of non pecuniary benefits (those which are not received in money) such as status, the respect of employees and/or the authority on them and even a comfortable workplace encourage me to continue in the company": The scenario reveals that almost $63 \%$ of the sample consider the non pecuniary benefits, besides the pecuniary ones, as an effort motivation factor. The statement got 3.66 average.

14. "I feel fulfilled in the company and do not consider the possibility of leaving my job in a short time": For $62 \%$ of the sample, replacing their current job for another one in the market is a remote possibility and that reflects positively in the company since staff turnover, the cost of selecting and hiring new employees and the risk of investing in training and having the benefited employee"s evasion from work decrease.

15. "I am always watching out for employment opportunities in other (several) companies": It shows a profile of a worker who is aware of the job market and the company should watch out for the possible job evasion of $41 \%$ of the sample, reflecting staff turnover.

16. "I think the company pays me above the market clearing wage and that motivates me to continue in the company": $45 \%$ of the sample do not consider the company remuneration a differential in the market in order to keep up the effort in their duti es and continue in the company. The aspect had an average of 2.68 .

17. "The work environment is favorable to boost my personal satisfaction of working in the company": $36 \%$ agree somehow; $62 \%$ strongly agree that the institutional and cultural environment of the current company contribute to the effort motivation of the workers. $24 \%$ neither disagree nor agree and $3 \%$ strongly disagree. The average is 3.71 .

18. "In my opinion, the ideas I have, either through suggestions or direct conversation with my supervisors, are taken into consideration in the company": $74 \%$ of the sample believe they have their suggestions taken into consideration by their supervisors, which infers, again, the good relationship between them. $20 \%$ neither disagree nor agree, $3 \%$ disagree somehow and $3 \%$ strongly disagree. The average in the 1 to 5 point scale was 3.89 .

19."Working under the pressure of a strict boss helps me improve my performance in the company": 44\% strongly disagree, $23 \%$ disagree somehow, summing up $67 \%$ who disagree with strict supervision as effort motivator. That brings a trade off to the company which needs to supervise workers in order to guarantee results, but at the same time, it needs to reduce costs and create a strategic supervision. The average was 2.12 .

20. "Overall, I feel motivated for working in the company": $68 \%$ of the sample feel at least partly encouraged to make an effort in their duties in the company, 30\% neither disagree nor agree, $11 \%$ disagree somehow and $1 \%$ strongly disagree. The average was 3.86

Source: Created by the authors 
Chart 2. Summary chart of the survey on remuneration, benefits and risks.

"I am risk averse and I consider the risk of dismissal": $42 \%$ of the sample agree, since the sample was clarified on risk definition. For the Shirking model, the cost of losing the job must be burdensome enough to encourage effort. The considerable abstention of opinion may reflect lack of the respondent's understanding on the risk taker idea.

"I am risk averse and I consider the risk of legal cases and probes in face of my performance": $50 \%$ of the respondents have no formed opinion. This statement aimed, at first, to quantify whether the employees assess the possibility of being subject to legal proceedings or being members of probes for acting in an illegal or unethical way in the duties delegated by the company. That is, the risk of penalty for not making the right effort is assessed by $29 \%$ who strongly agree and $21 \%$ who strongly disagree. The later ones are not probably in a position of industrial confidentiality or in a favorable position to generate cartels, monopolies and oligopolies which are prohibited by law and which the company, in many occasions forces an agreement with penalty for the employee who commits fraud. The incentive to keep the posture expected in the company is in the risk of the penalty being imputable and $29 \%$ of the sample sees such measure.

$62.63 \%$ of the sample strongly agree with "I consider the benefits offered by the company motivating and higher than those offered by other companies in the market in the same sector". We take as benefits, advantages besides the salary, which is not recognized as above market clearing, as it had already been analyzed in the Summary I section. Here, the employees took into account the pecuniary benefits besides their fixed wage, such as individual and familiar health insurance, and the nonpecuniary benefits (status and recognized authority) were also considered. $17.17 \%$ have no formed opinion and $20.20 \%$ strongly disagree. The later ones consider that the total benefits offered by the company are not higher than those offered by the market and/or are not worth to make an effort on the tasks delegated by the company.

"The doubts regarding the paychecks are elucidated fast, right when the work contract is signed" shows, once more, the company transparency assessment as the second statement of this section. $64.65 \%$ strongly agree, $17.17 \%$ have no formed opinion and $18.18 \%$ strongly disagree. The discrepancy might come from the feeling of lack of elucidation regarding overtime, bonuses and others by the company.

"The definitions of goals and objectives are suitable and interfere fairly in the paycheck", $39 \%$ of the sample strongly agree, $16 \%$ do not have formed opinion and the $45 \%$ majority strongly disagree. That shows that, basically, half of the respondent employees believe that the goals and objectives of the company are forced up in order to maximize the workers' efforts and many of the goals are considered unreachable due to, perhaps, some market recession or seasonality. Not reaching the goal and the budget jeopardization is seen by $45 \%$ of the sample as unfair or statistic with bias for the calculation of remuneration.

"I consider the full remuneration fair when compared to the rest of the market": it also reflects the internal understanding of the employee in face of his paycheck compared to the available market data. $48 \%$ strongly agree, $18 \%$ do not have formed opinion and $34 \%$ strongly disagree. The analysis of the previous statement has direct influence in this question, as well as the analy sis of the sixteenth statement of section 1 of the survey.

Source: Created by the authors (2018). 
Ideas listened by the bosses - $\%$

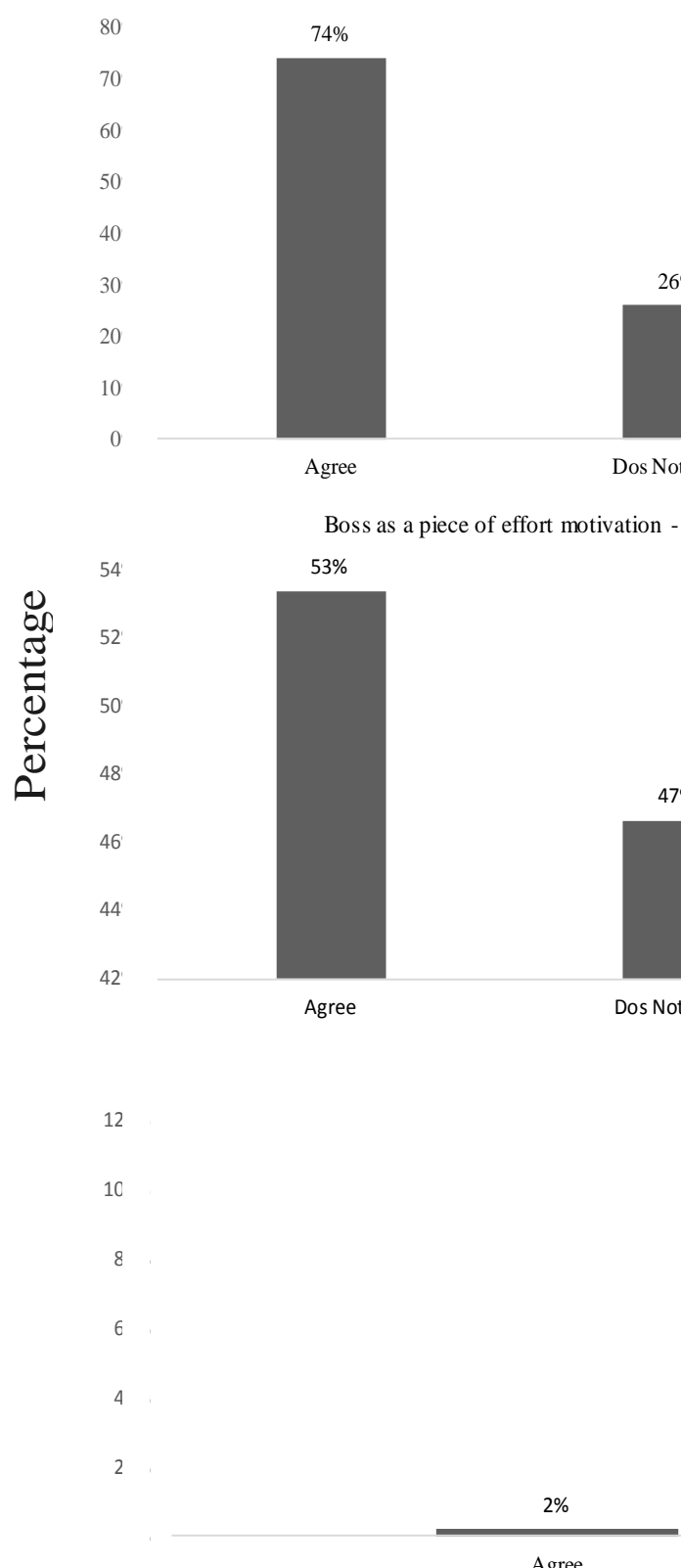

Boss's strictness and worker's performance- \%

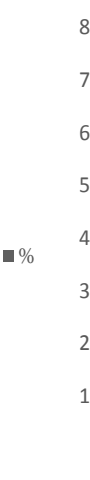

80

$70-67 \%$

60

50

$26 \%$

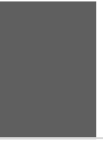

Not Agree
$\%$

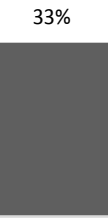

Agree

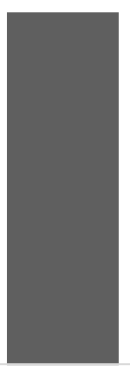

Dos Not Agree

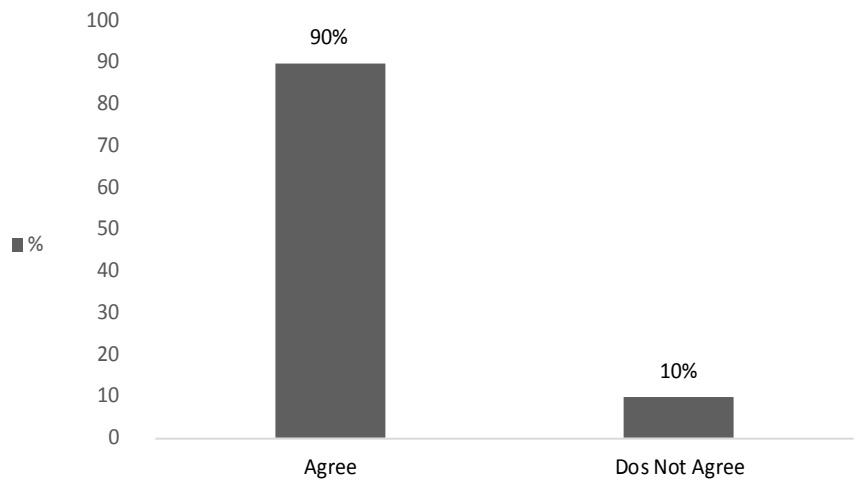

Wage is the greatest motivator- $\%$

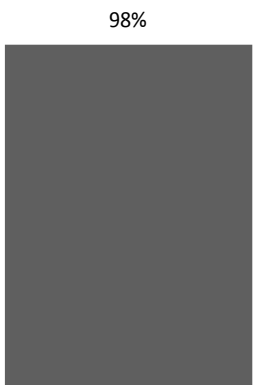

Dos Not Agree

Figure 1. The sample's perceptions. 